\title{
ERRATUM
}

\section{Gender and psychological well-being in older adults - ERRATUM}

\section{Pilar Matud, Juan Manuel Bethencourt, Ignacio Ibáñez, and Demelza Fortes}

DOI: https://doi.org/10.1017/S1041610220000824, Published by Cambridge University Press, 27 May 2020

Key words: gender differences, social support, health aging, erratum

The above article (Matud et al., 2020) published with Juan Manuel Bethencourt's name appearing incorrectly.

The original article has been corrected online to rectify this error.

\section{Reference}

Matud, M. P., Bethencourt, J. M., Ibáñez, I., and Fortes, D. (2020). Gender and psychological well-being in older adults. International Psychogeriatrics, 32(11), 1293-1302. doi: 10.1017/S1041610220000824. 